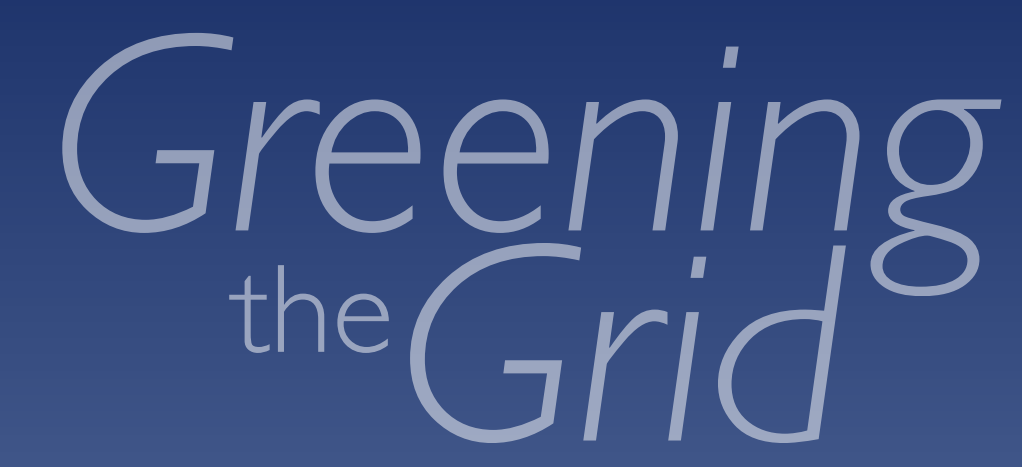

\title{
Tamil Nadu
}

Pathways to Integrate 175 Gigawatts of Renewable Energy into India's Electric Grid

State-specific results from Volume II, which includes all of India. The full reports include detailed explanations of modeling assumptions, results, and policy conclusions. 


\section{Assumptions About Infrastructure, Demand, and Resource Availability in $\mathbf{2 0 2 2}$}

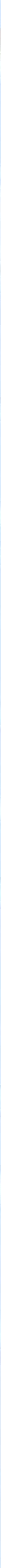




\section{Assumptions about RE and conventional generation and transmission}

in Tamil Nadu in 2022
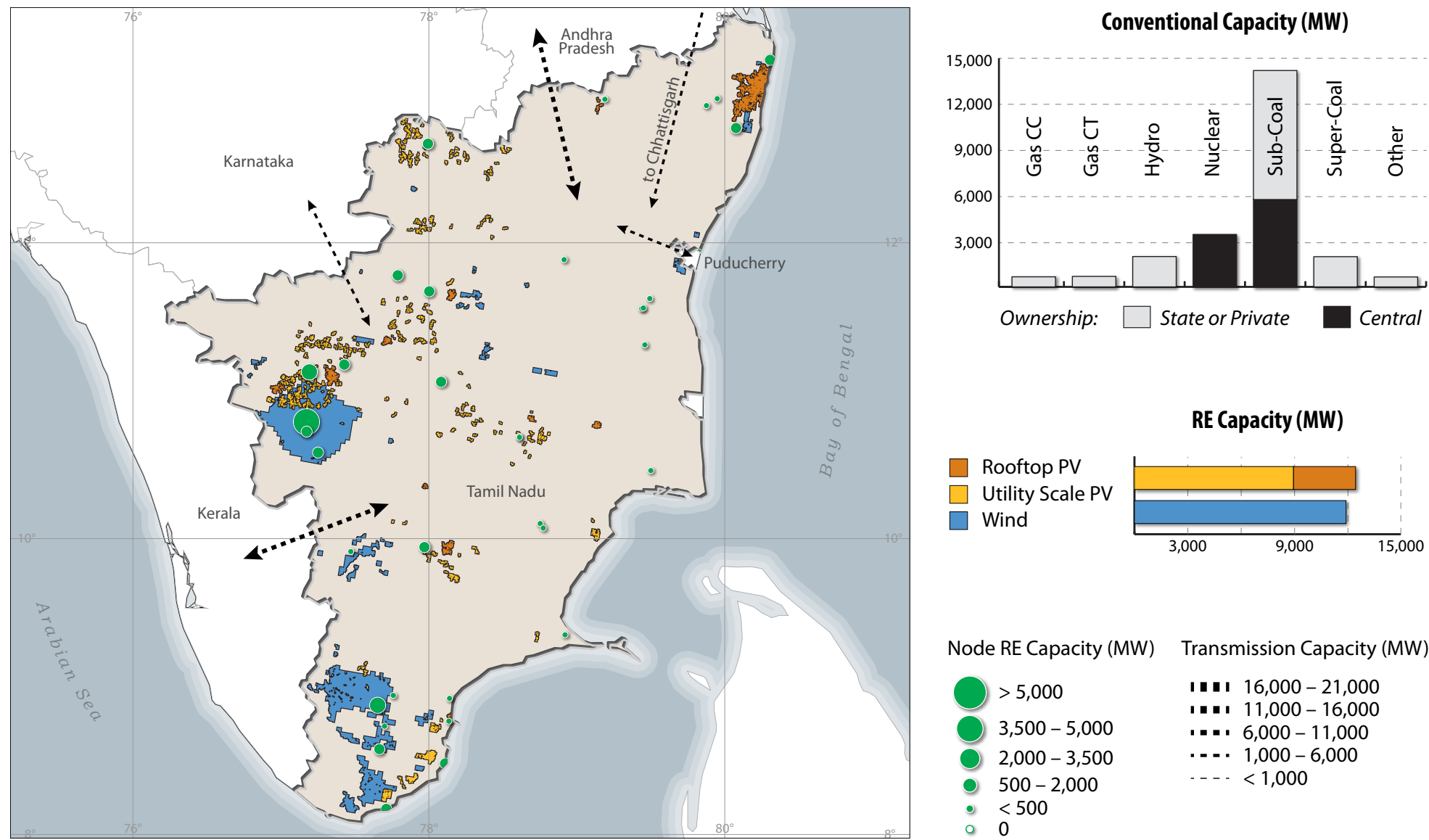

\begin{tabular}{lc}
\hline Peak load (GW) & 25 \\
\hline $\begin{array}{l}\text { Total annual load } \\
(\text { TWh })\end{array}$ & 316 \\
\hline $\begin{array}{l}\text { Installed non-RE } \\
\text { capacity (GW) }\end{array}$ & 24 \\
\hline $\begin{array}{l}\text { Installed RE capacity } \\
\text { (GW) }\end{array}$ & 24 \\
\hline $\begin{array}{l}\text { Total import/export } \\
\text { capacity (GW) }\end{array}$ & 29 \\
\hline
\end{tabular}

NREL and LBNL selected RE sites based on the methodology explained in Volume I of this report, which is available at www.nrel.gov/docs/fy/7osti/68530.pdf.

Rooftop PV has been clubbed to the nearest transmission node.

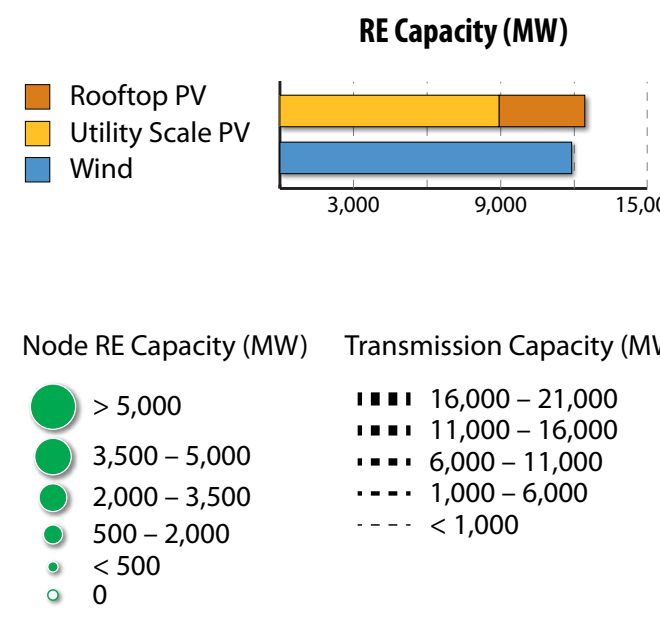

Tamil Nadu has 35 tie-lines connecting it to other states in this model. 


\section{Tamil Nadu Resource Availability in 2022}

Available wind, solar, and hydro energy throughout the year in Tamil Nadu
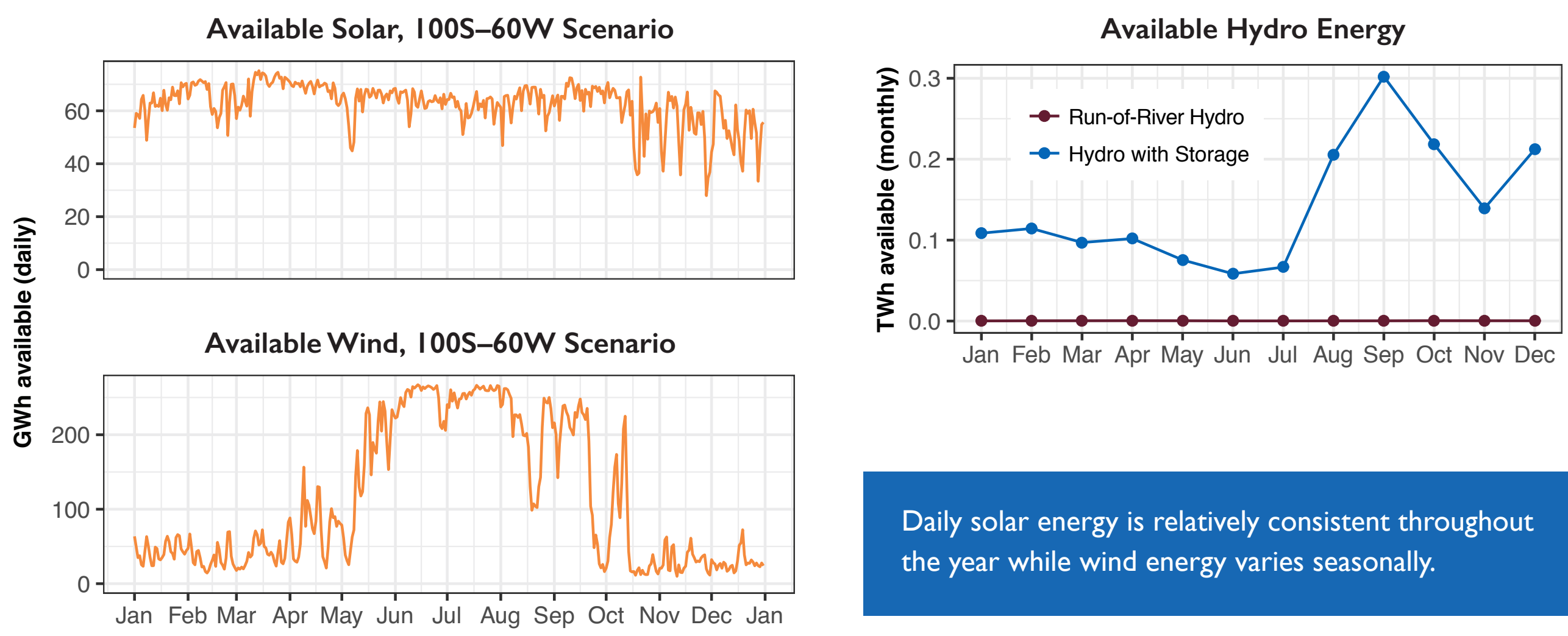

Note: Y-axis is different for each resource

Daily solar energy is relatively consistent throughout the year while wind energy varies seasonally. 


\title{
Operation in Tamil Nadu with Higher Levels of RE:
}

\author{
RE Penetration in 2022
}




\section{Increased amounts of RE available in Tamil Nadu change Tamil Nadu's generation mix and therefore the operation of the entire fleet.}

Annual energy generation in Tamil Nadu

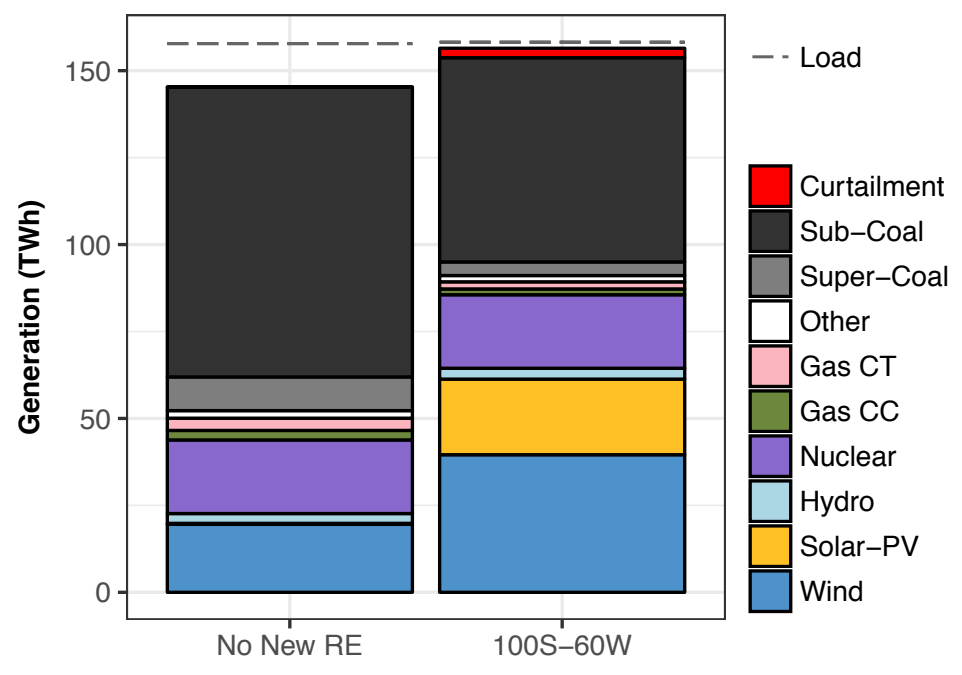

$24 \mathrm{GW}$ of wind and solar power generates 6 I TWh annually.
Monthly RE generation and load in Tamil Nadu in the I00S-60W scenario

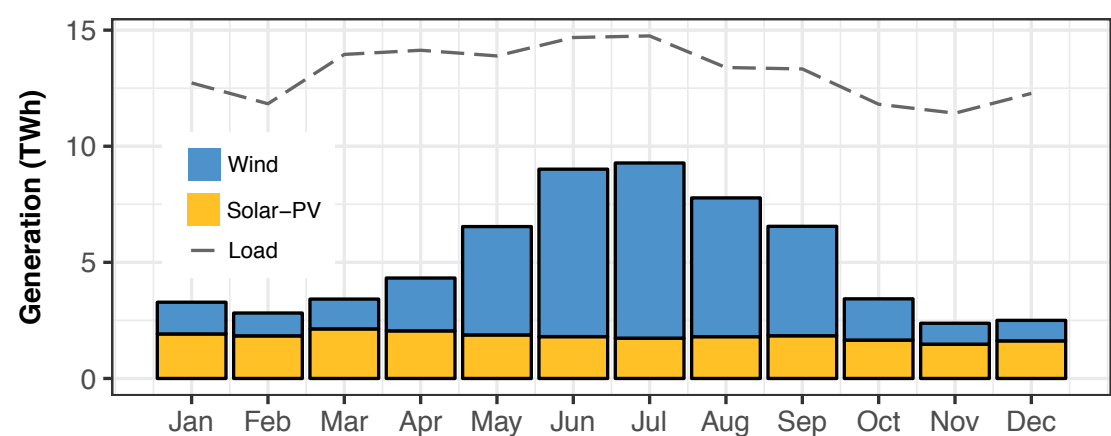

RE penetration by load and generation

\section{00S-60W}

\begin{tabular}{lc}
\hline Percent time over $50 \%$ of load & 33 \\
\hline Peak RE \% of load & 100 \\
\hline Percent time over $50 \%$ of generation & 37 \\
\hline Peak RE \% of generation & 82
\end{tabular}

Wind and

solar produce

$40 \%$ of total

generation in

Tamil Nadu

and meet 39\%

of load.
Coal generation

falls by $33 \%$

and gas by $41 \%$

between No

New RE and

l00S-60W. 


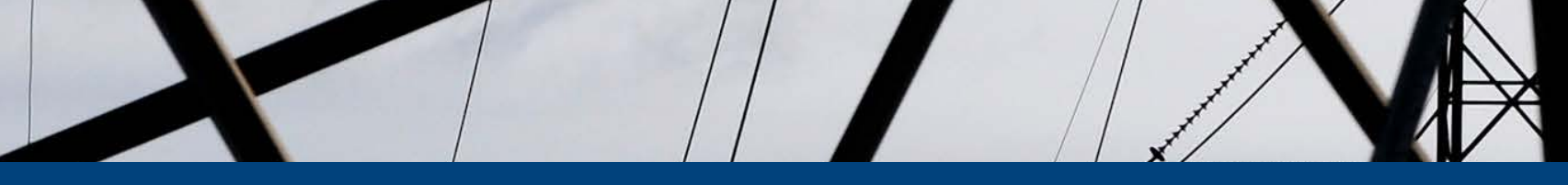

Operation in Tamil Nadu with Higher Levels of RE: Imports and Exports

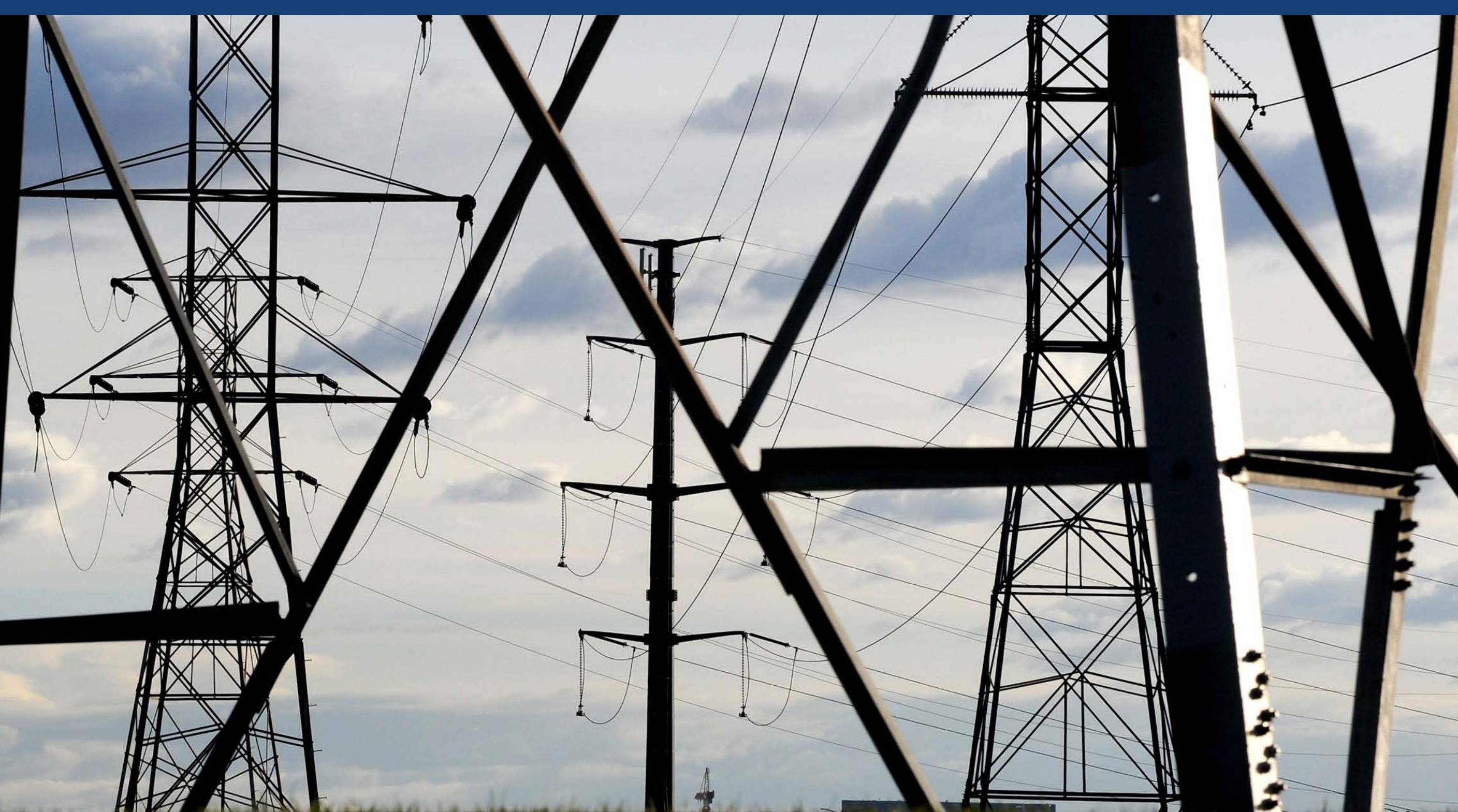




\section{Increased RE generation inside and outside of Tamil Nadu affects flows with surrounding states.}

Tamil Nadu's increased RE generation allows it to reduce imports from Chhattisgarh. The state also reduces its net exports to Karnataka, Kerala, and Andhra Pradesh, which likewise are relying more on their local $R E$ generation. The shift in flows away from traditional corridors contributes to a $56 \%$ increase in periods when in-state congestion affects dispatch.
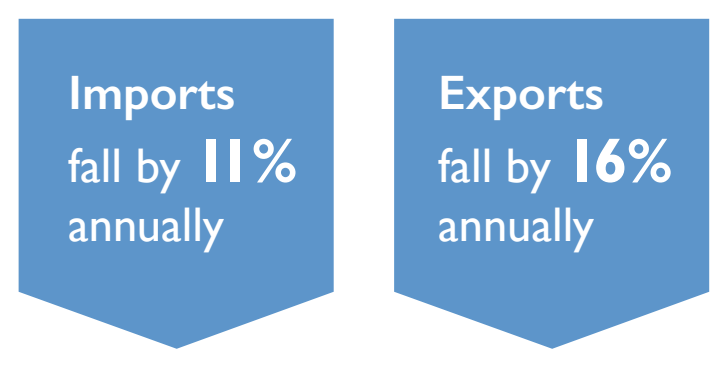

\section{SCENARIO} NET EXPORTS (TWH)

\begin{tabular}{lll}
\hline No New RE & -12 & net importer \\
\hline IOOS-60W & -4.4 & net importer \\
\hline
\end{tabular}

Distribution of flows across state-to-state corridors

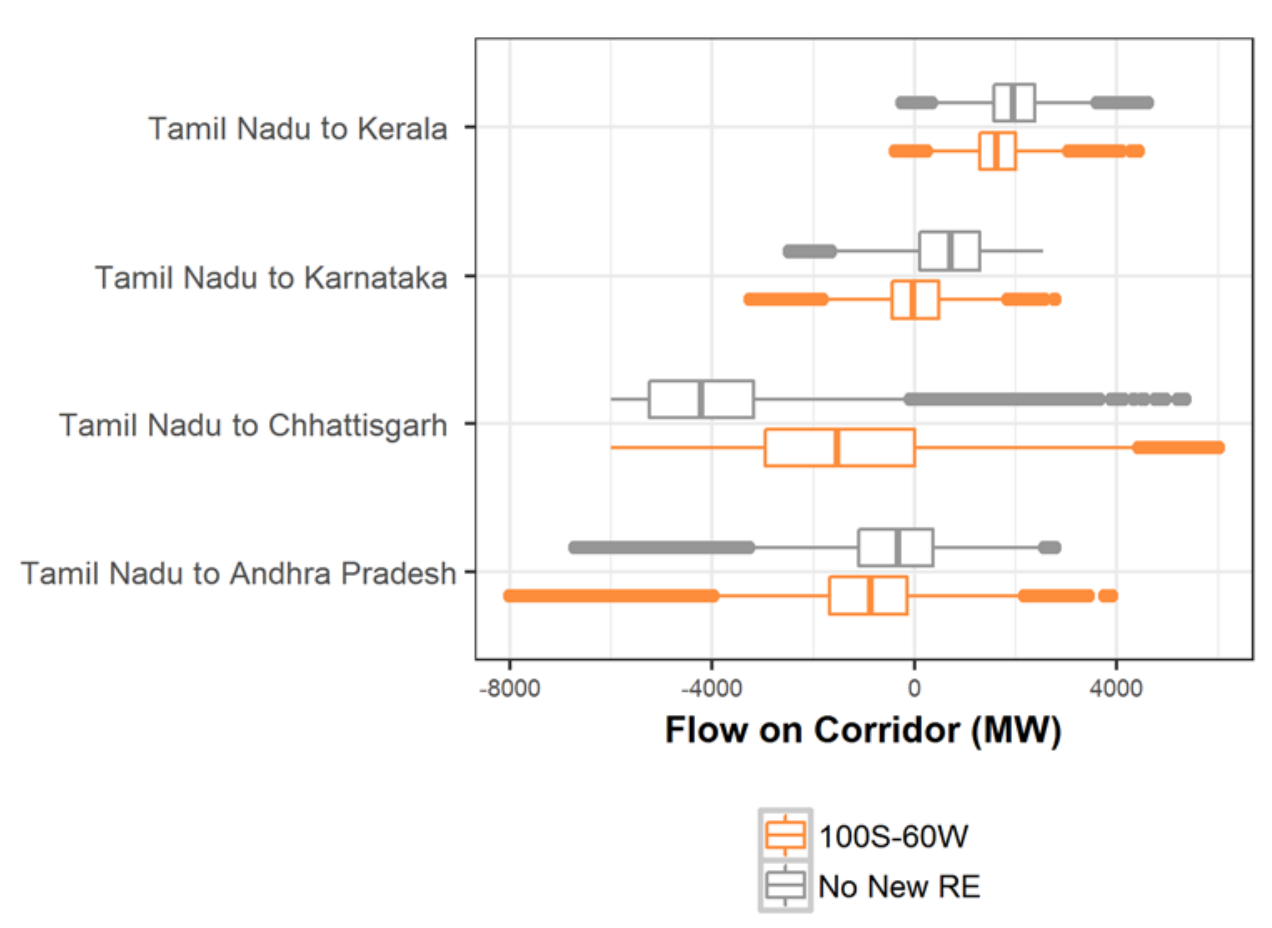


Operation in Tamil Nadu with Higher Levels of RE: Rest of the Fleet

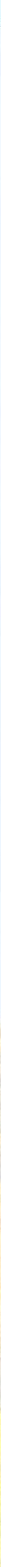


The addition of RE in Tamil Nadu changes net load, which is the load that is not met by RE and therefore must be met by conventional generation. Due to changes in net load, hydro and thermal plants operate differently in higher RE scenarios.

Example days of load and net load in Tamil Nadu

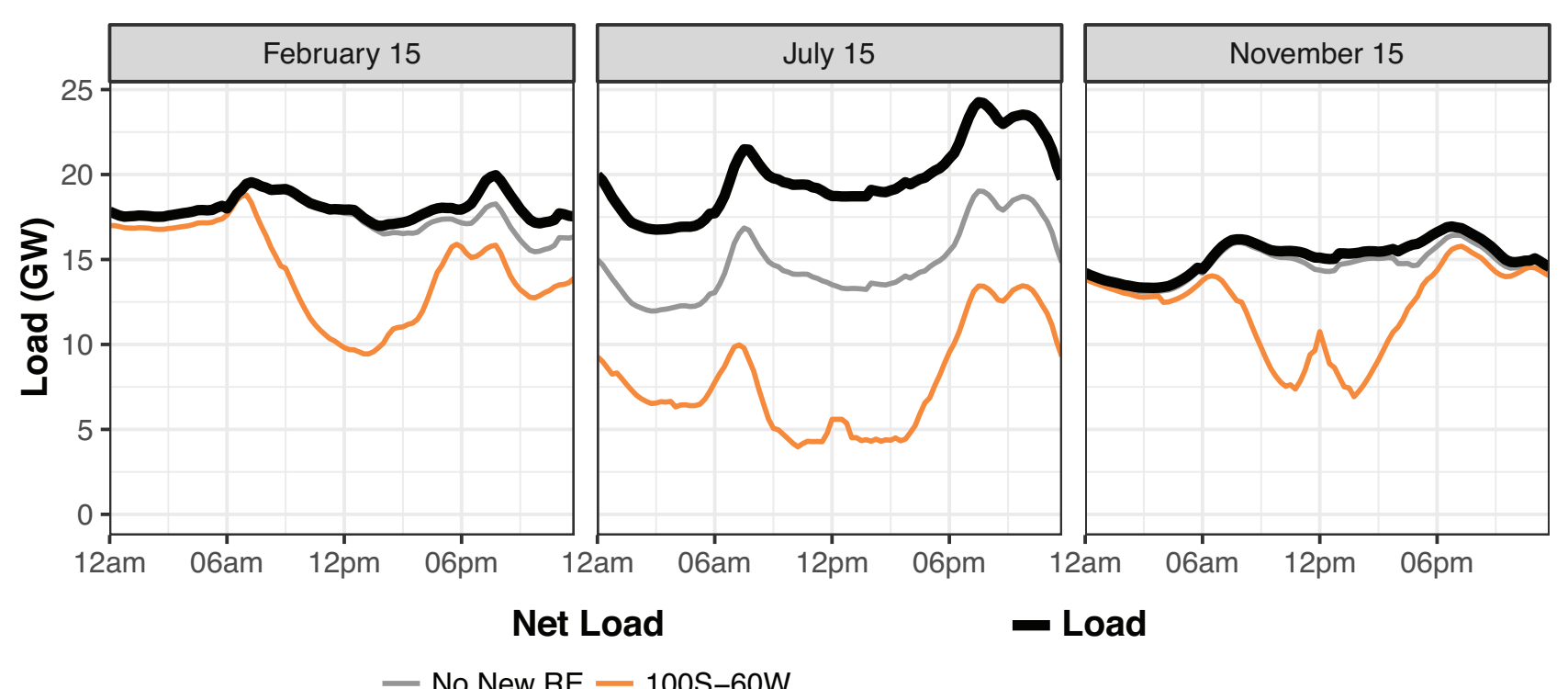

Peak I-hour net load up-ramp in the I00S-60W scenario is $8.2 \mathrm{GW}$, up from $4.7 \mathrm{GW}$ in the No New RE scenario.
Maximum net load valley-to-peak ramp is $14 \mathrm{GW}$ in the I00S-60W scenario, up from $8.6 \mathrm{GW}$ in the No New RE scenario.
Increased daytime solar generation causes a dip in net load, which requires Tamil Nadu to either increase net exports, turn down its thermal generators, or curtail RE. On I 5 July, increased monsoon season wind generation reduces Tamil

Nadu's net load throughout the day.

Hourly net load ramps for all periods of the year, ordered by magnitude

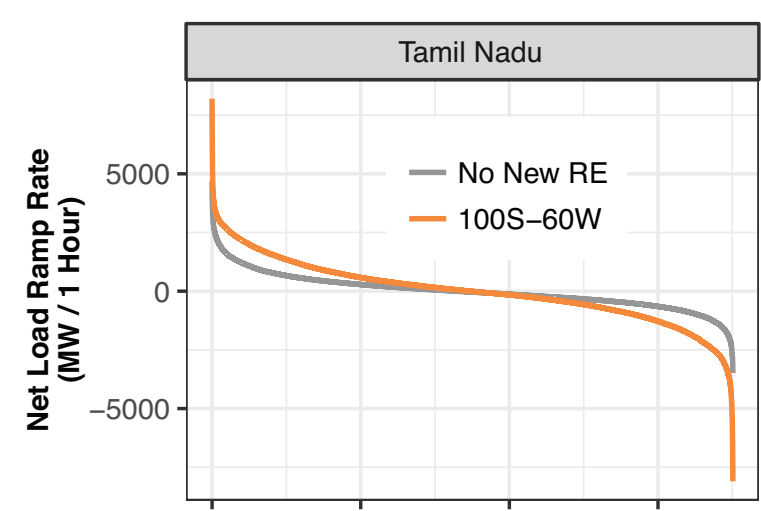




\section{Changes to Tamil Nadu's Coal Fleet Operations}

Operational impacts to coal

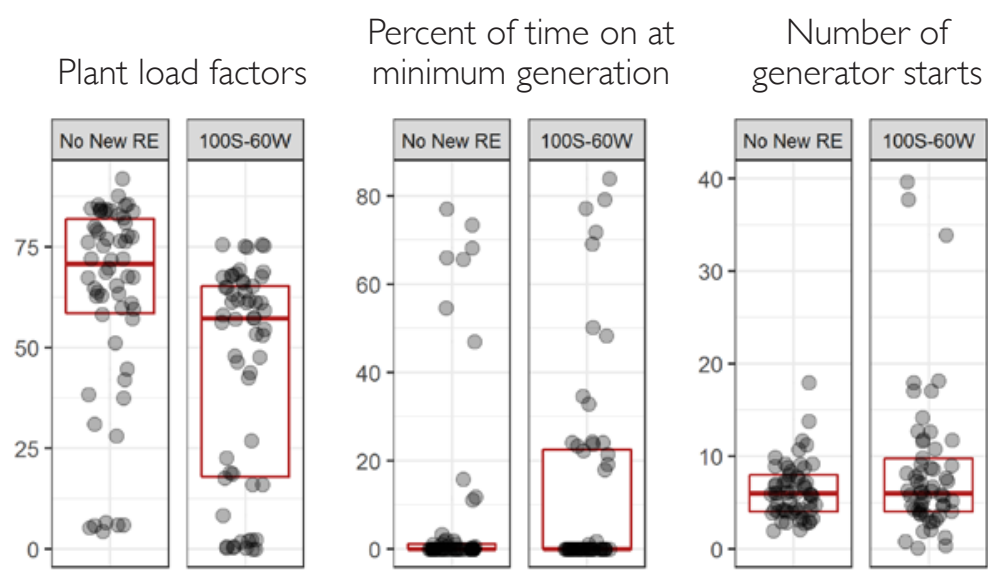

Coal plant load factors (PLFs) are lower in the 100S-60W scenario due to more frequent cycling and operation at minimum generation levels.
While coal

PLFs are lower

fleetwide in

I00S-60W,

the most

expensive

generators

experience the

greatest drop

in PLF.
Average PLF of coal generators in Tamil Nadu, disaggregated by variable cost

\begin{tabular}{lll}
\hline RELATIVE VARIABLE COST & NO NEW RE & I O0S-60W \\
\hline Lower I/3 & 76 & 66 \\
\hline Mid I/3 & 79 & 58 \\
\hline Higher I/3 & 43 & 12 \\
\hline Fleetwide & 66 & 44 \\
\hline
\end{tabular}

One week of coal operation in Tamil Nadu

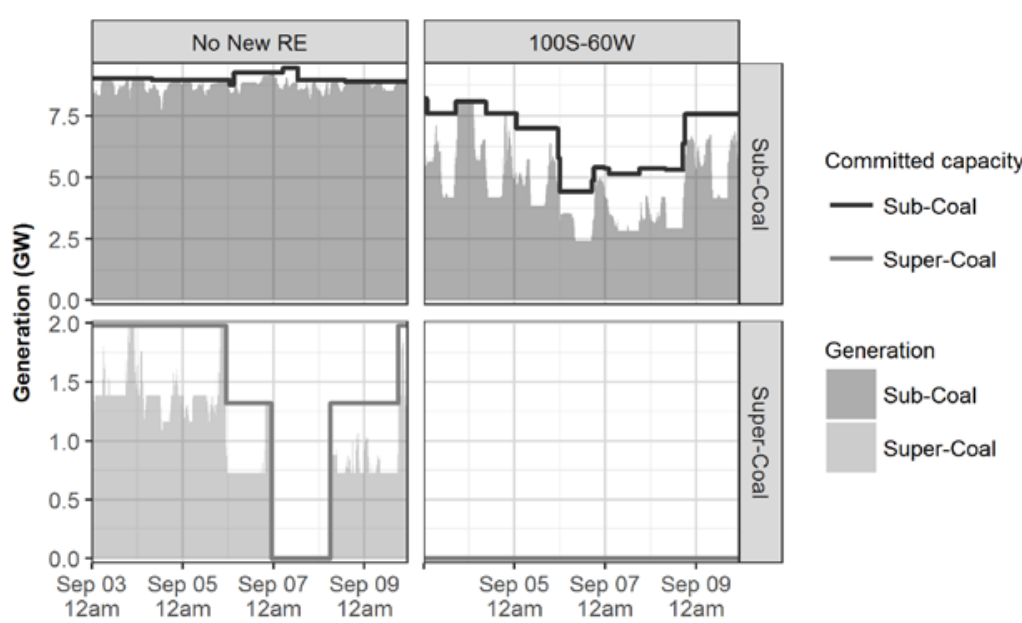

The coal fleet is turned off more and its output varies daily due to midday availability of solar power in the 100S-60W scenario. 


\section{Changes to Tamil Nadu's Hydro Fleet Operations}

Average day of hydro in Tamil Nadu by season

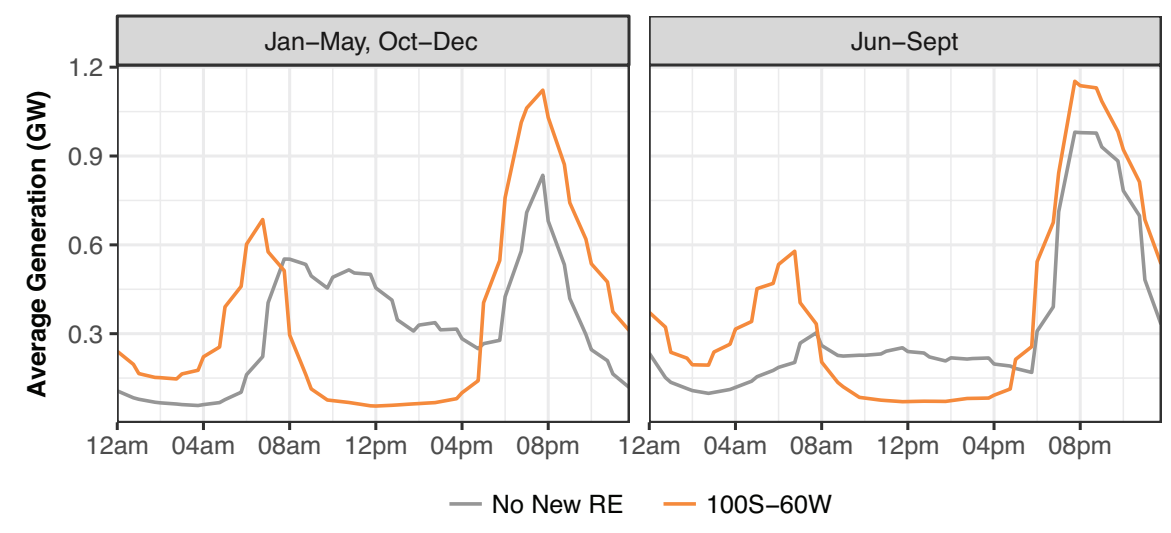

Tamil Nadu is able to utilize most of the flexibility available in hydro in both nonmonsoon and monsoon seasons. This is partially aided by the flexibility supplied from pumped hydro.

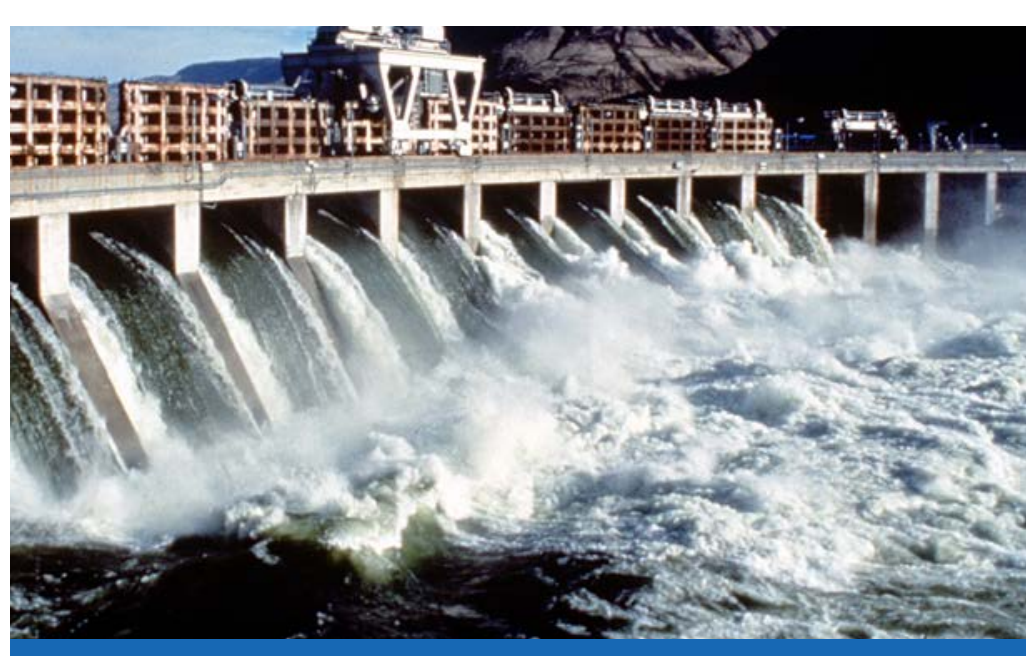

Hydro plants follow a more pronounced two-peak generation profile due to availability of solar power during the middle of the day. 
Curtailment levels indicate how efficiently RE is integrated. Large amounts of curtailment signal inflexibility in the system, preventing grid operators from being able to take full advantage of the available renewable resources.

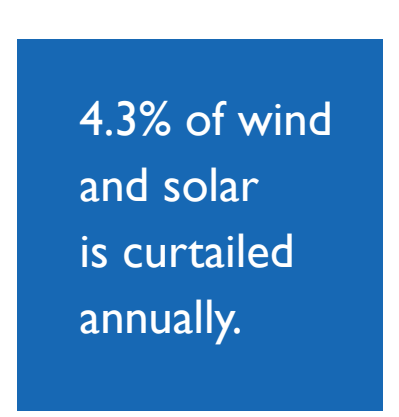

Total daily curtailment throughout the year in Tamil Nadu

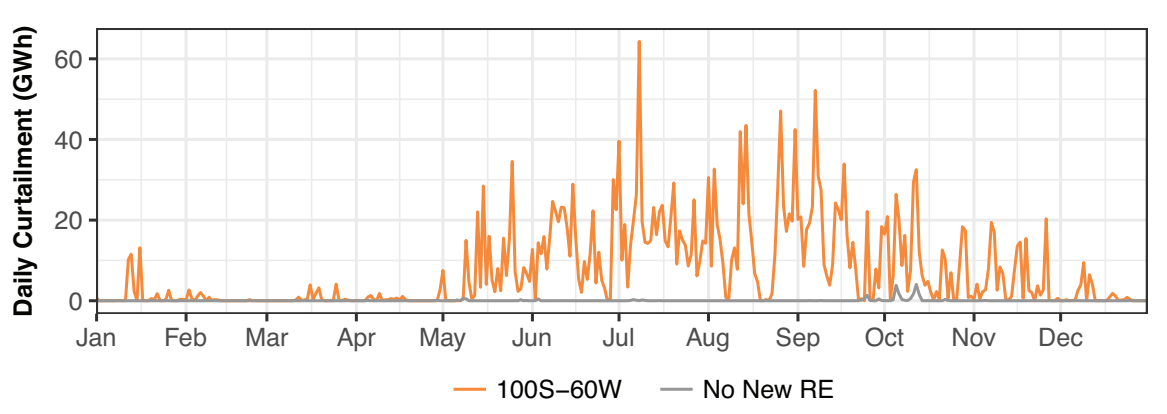
Almost
all of RE
curtailment
occurs in
$8.4 \%$ of
periods in
the year.

Average daily curtailment in March and July

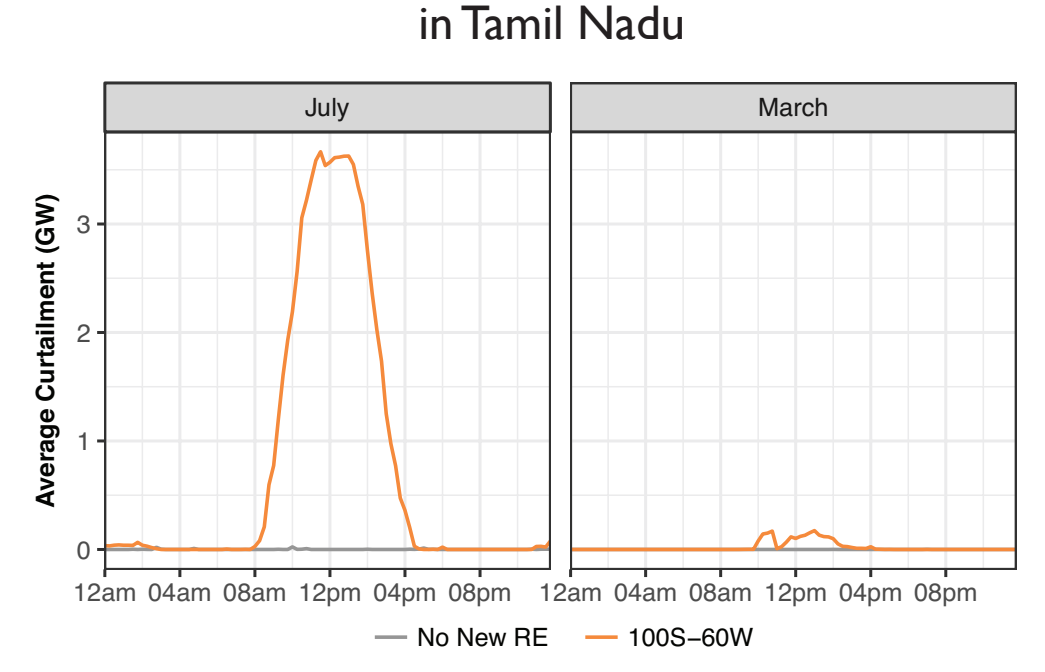

Tamil Nadu's RE curtailment is relatively low from January through April but rises during the monsoon season, and this persists through November. In-state congestion affects its dispatch for $56 \%$ of the year, and for $13 \%$ of the year its thermal fleet is fully inflexible. Both of these factors contribute to RE curtailment. Tamil Nadu's geographic location can restrict access to external markets, making adequate local thermal and transmission flexibility especially important.

RE curtailment as a percent of available energy by substation (each dot represents a substation)

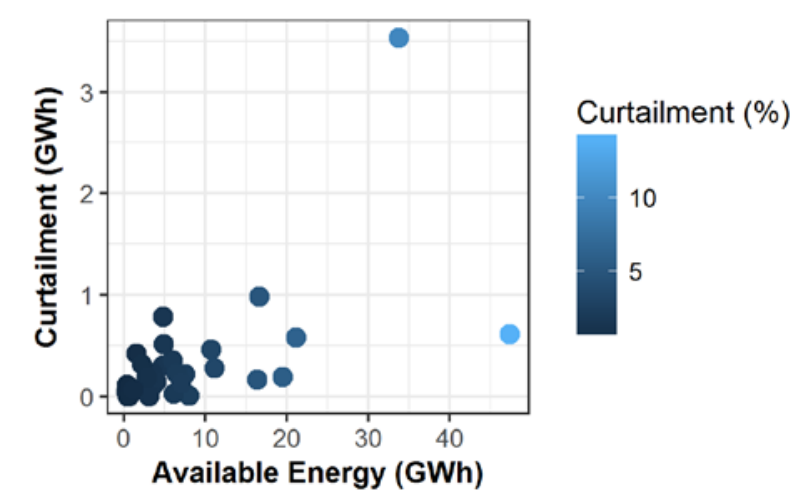


Examples of Dispatch During Interesting Periods in Tamil Nadu

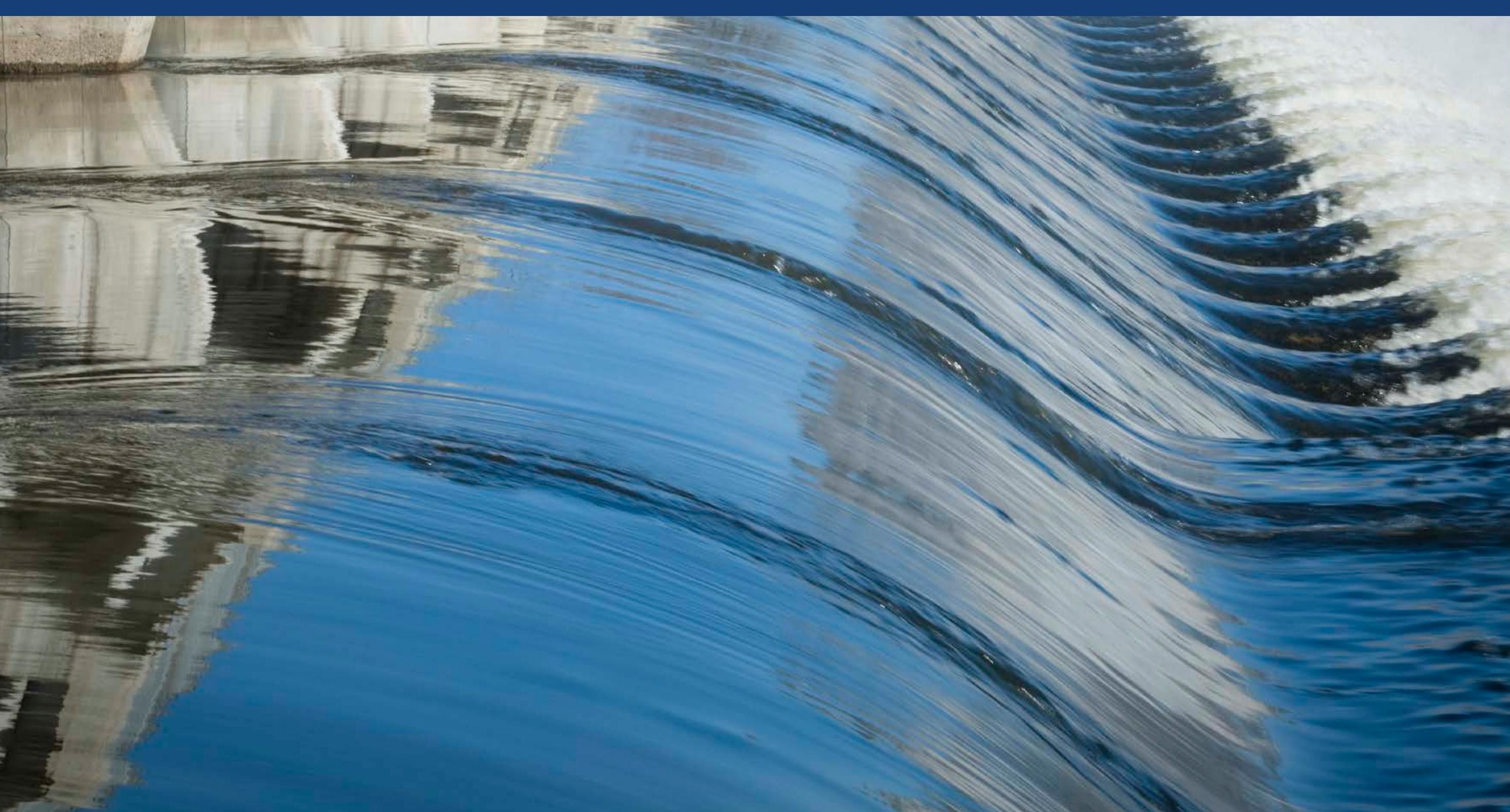




\section{The following pages show dispatch in Tamil Nadu during several interesting}

periods throughout 2022 . The vertical magenta line highlights the dispatch interval associated with the figure title.

High load period: Generation, load, and interchange (values in GW unless otherwise specified)

\begin{tabular}{lllllllllll}
\hline $24 \mathrm{June} 8: 45 \mathrm{pm}$ & & & & & & & & & \\
\hline LOAD & CURTAILMENT & HYDRO & NUCLEAR & OTHER & COAL & GAS & RE & $\begin{array}{l}\text { NET } \\
\text { IMPORTS }\end{array}$ & $\begin{array}{l}\text { RE PENETRA- } \\
\text { TION (\%) }\end{array}$ \\
\hline 25.3 & 0 & 1.6 & $\mathrm{I}$ & 0.6 & 7.5 & 0.7 & 11.2 & 2.5 & 44
\end{tabular}
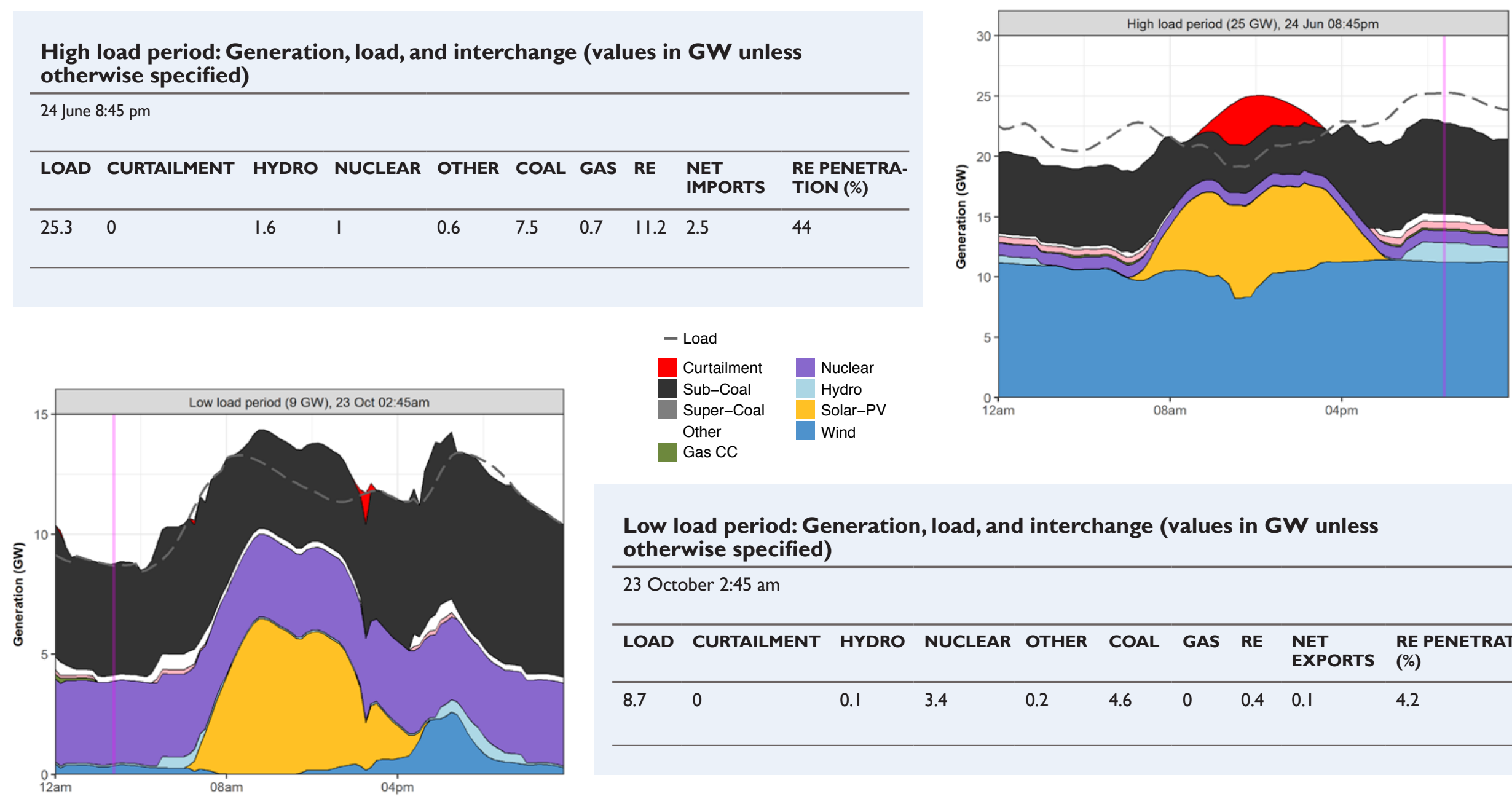

Low load period: Generation, load, and interchange (values in GW unless otherwise specified)

23 October 2:45 am

\begin{tabular}{llllllllll}
\hline LOAD & CURTAILMENT & HYDRO & NUCLEAR & OTHER & COAL & GAS & RE & $\begin{array}{l}\text { NET } \\
\text { EXPORTS }\end{array}$ & $\begin{array}{l}\text { RE PENETRATION } \\
(\%)\end{array}$ \\
\hline 8.7 & 0 & 0.1 & 3.4 & 0.2 & 4.6 & 0 & 0.4 & 0.1 & 4.2
\end{tabular}




\section{Example Dispatch Days}

High RE period: Generation, load, and interchange (values in GW unless otherwise specified)

\begin{tabular}{lllllllllll}
\hline 2 June $12: 45 \mathrm{pm}$ & & & & & & & \\
\hline LOAD & CURTAILMENT & HYDRO & NUCLEAR & OTHER & COAL GAS & RE & $\begin{array}{l}\text { NET } \\
\text { EXPORTS }\end{array}$ & $\begin{array}{l}\text { RE PENETRA- } \\
\text { TION (\%) }\end{array}$ \\
\hline 22.5 & 0.1 & 0 & 2.2 & 0 & 3.3 & 0 & 19.4 & 2.5 & 86
\end{tabular}
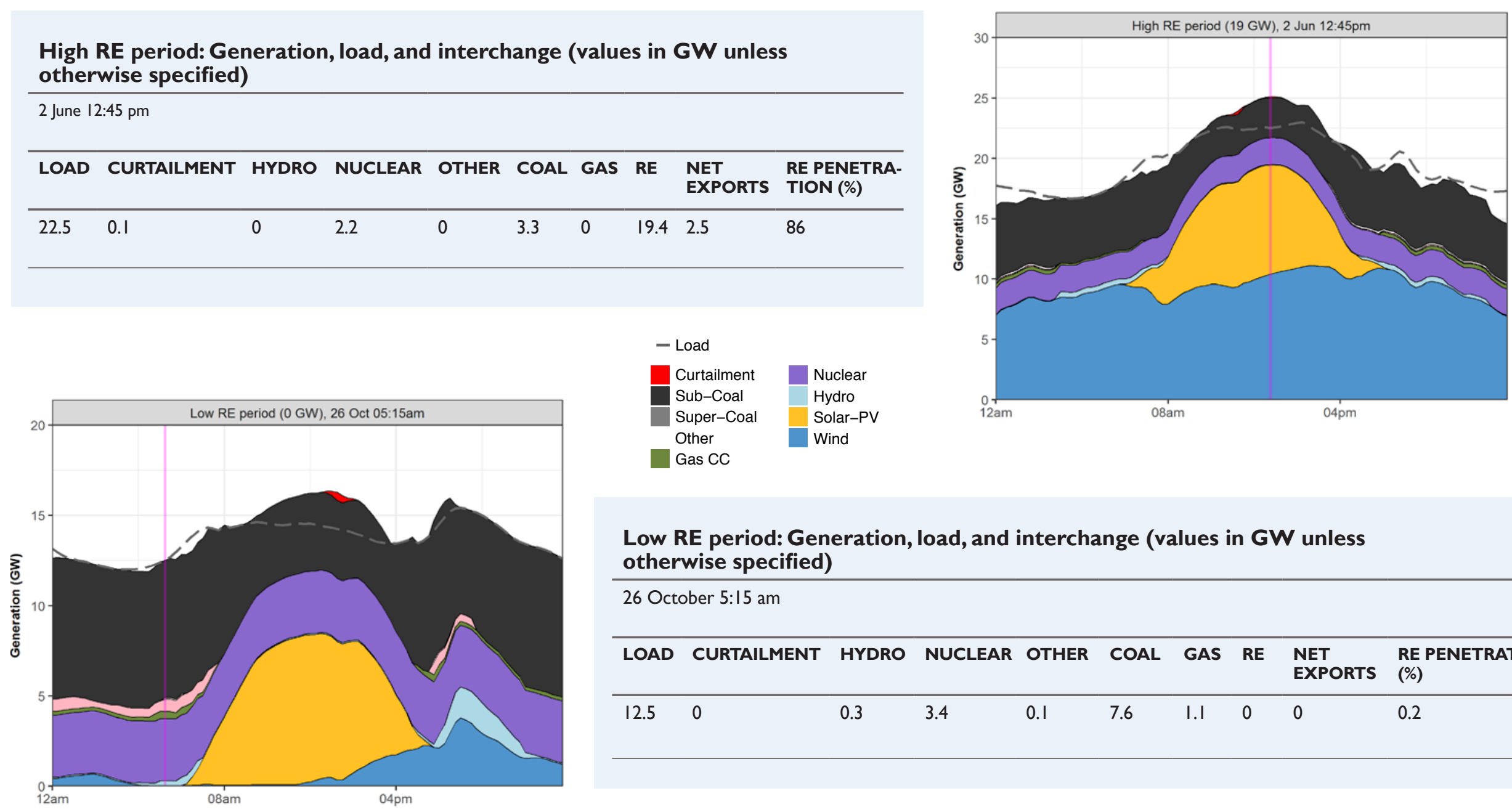

Low RE period: Generation, load, and interchange (values in GW unless otherwise specified)

26 October 5:15 am

\begin{tabular}{llllllllll}
\hline LOAD & CURTAILMENT & HYDRO & NUCLEAR & OTHER & COAL & GAS & RE & $\begin{array}{l}\text { NET } \\
\text { EXPORTS }\end{array}$ & $\begin{array}{l}\text { RE PENETRATION } \\
(\%)\end{array}$ \\
\hline 12.5 & 0 & 0.3 & 3.4 & 0.1 & 7.6 & 1.1 & 0 & 0 & 0.2
\end{tabular}




\section{Example Dispatch Days}

High curtailment period: Generation, load, and interchange (values in GW unless otherwise specified)

25 May 1 I:45 am

\begin{tabular}{llllllllll}
\hline LOAD & CURTAILMENT & HYDRO & NUCLEAR & OTHER & COAL GAS & RE & $\begin{array}{l}\text { NET } \\
\text { EXPORTS }\end{array}$ & $\begin{array}{l}\text { RE PENETRA- } \\
\text { TION (\%) }\end{array}$ \\
\hline 17.3 & 6.8 & 0 & 3 & 0 & 2.7 & 0 & 12.7 & 1.2 & 74
\end{tabular}

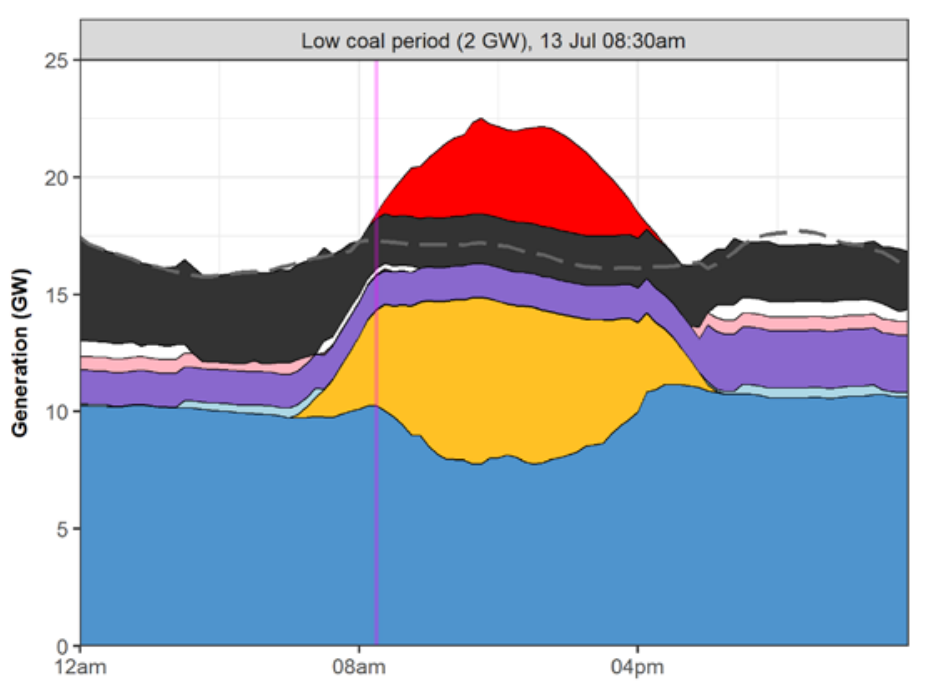

- Load

Curtailmen

Sub-Coal

Super-Coal

Other

Gas CC

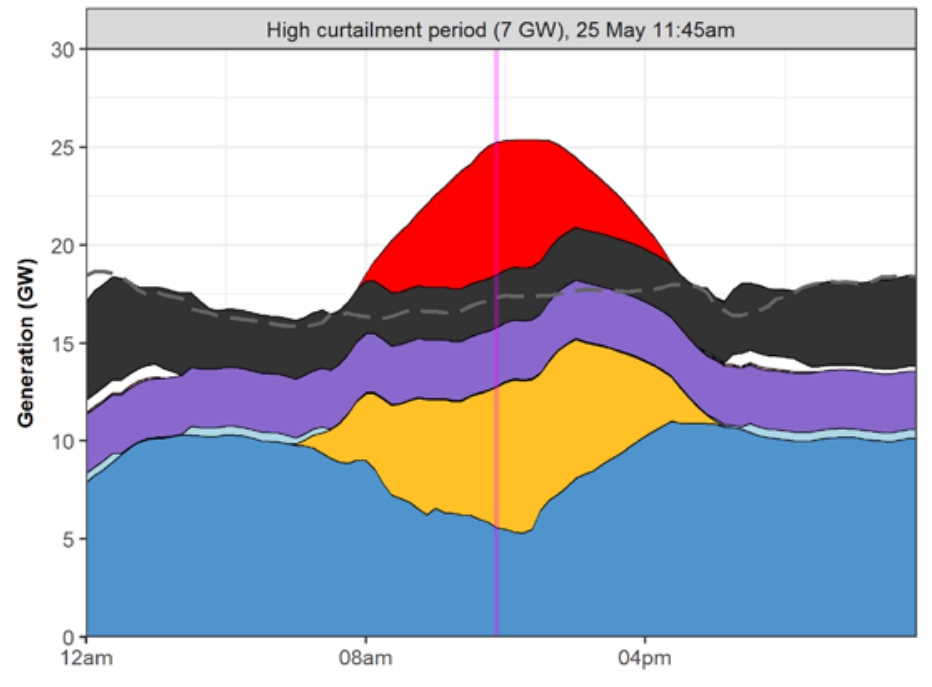

Low coal period: Generation, load, and interchange (values in GW unless otherwise specified)

13 July $8: 30$ am

LOAD CURTAILMENT HYDRO NUCLEAR OTHER COAL GAS RE NET RPORTS

\begin{tabular}{llllllllll}
\hline 17.3 & 0.2 & 0 & 1.4 & 0.2 & 2.1 & 0.1 & 14.4 & 0.9 & 83
\end{tabular}




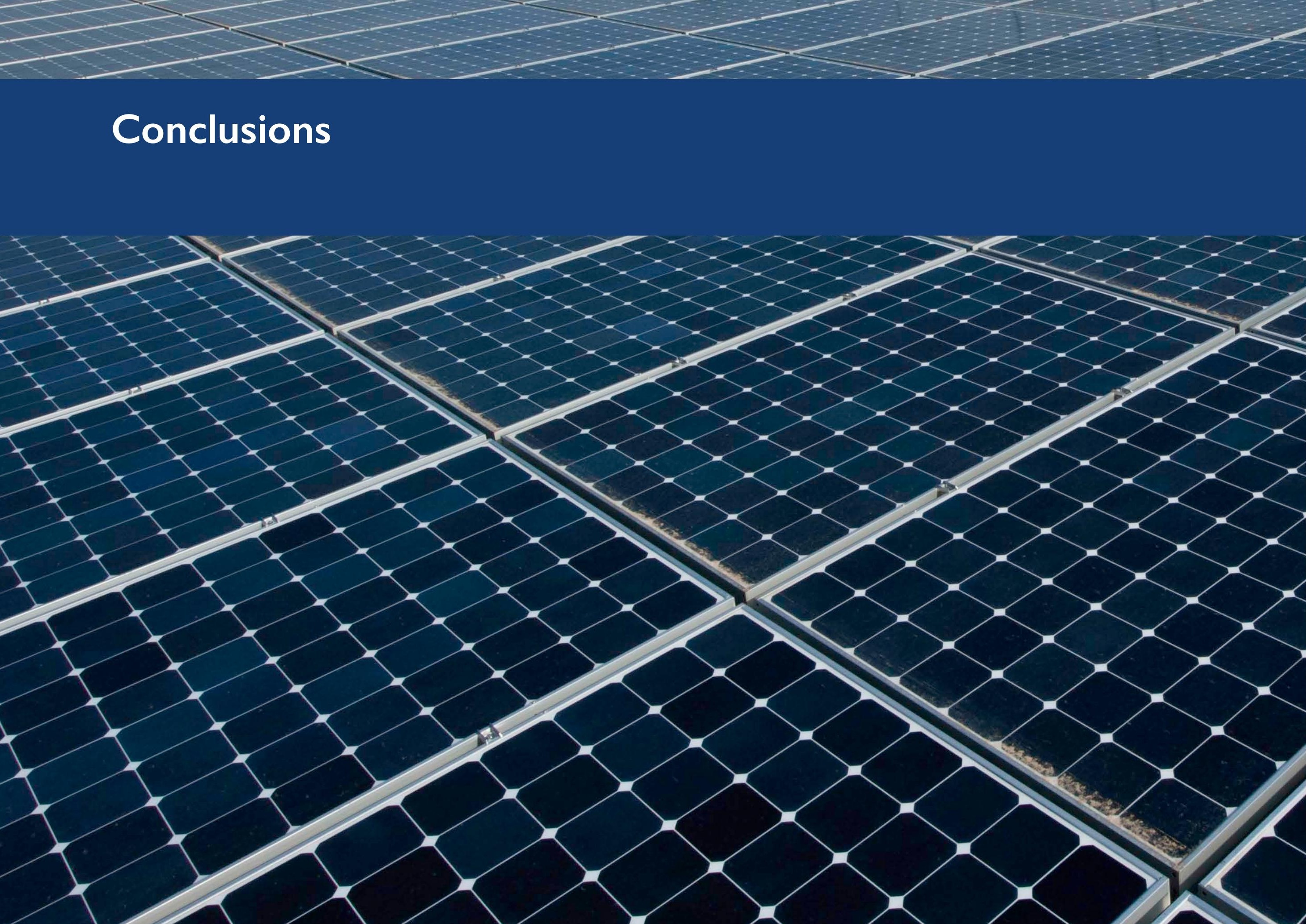


Based on this study's assumptions about demand and installed generation and transmission capacity in Tamil Nadu and nationwide, Tamil Nadu can integrate the equivalent of $40 \%$ of its total generation in 2022 with $4.3 \%$ annual wind and solar curtailment. This changes the way Tamil Nadu's grid must operate. Compared to a 2022 system with no new RE, net exports rise by $36 \%$ annually, and the PLF of the coal fleet falls from $66 \%$ to $44 \%$.
Because Tamil Nadu borders the ocean with limited interstate transmission capacity, it is especially affected by constraints in Andhra Pradesh, in Karnataka, and on the Southern-toWestern-region interface. Regionwide solutions will be especially impactful to Tamil Nadu because of these factors. 


\section{What can the state do to prepare for higher RE futures?}

Establish process for optimizing locations and capacities for RE and transmission; inadequate transmission has a large effect on RE curtailment in the model. This requires good information on possible areas for RE locations.

Match or exceed CERC guidelines for coal flexibility. Reducing minimum operating levels for coal plants has the largest impact to RE curtailment among all integration strategies evaluated.

Consider mechanisms to better coordinate scheduling and dispatch with neighbors, which can reduce production costs and allow each state to better access least-cost generation, smooth variability and uncertainty, and better access sources of system flexibility.
Create a new tariff structure for coal that specifies performance criteria (e.g., ramping), and that addresses the value of coal as PLFs decline.

Create model PPAs for RE that move away from must-run status and employ alternative approaches to limit financial risks.

Use PPAs to require RE generators to provide grid services such as automatic generation control and operational data.

\section{Create policy and regulatory} incentives to access the full capabilities of existing coal, hydro, and pumped storage.

Require merit order dispatch based on system-wide production costs; supplementary software may be required.
Improve the production cost model built for this study to address statespecific questions.

Institute organization and staff time to maintain the model over time.

Update power flow files to include more information related to high RE futures; conduct dynamic stability studies.

Adopt state-of-the-art load and RE forecasting systems.

Address integration issues at the distribution grid, including rooftop PV and utility-scale wind and solar that is connected to low voltage lines.

For a broader set of policy actions, see the executive summary for the National Study at www.nrel.gov/ docs/fy/7osti/68720.pdf. 


\section{Ways to use the model for state planning}

You can use this model for operational and planning questions such as:

What is the effect on operations of different reserve levels?

How will changes to operations or new infrastructure affect coal cycling?

What is the impact on dispatch of changes to market designs or PPA requirements?

How will different RE growth scenarios affect fuel requirements and emissions targets?

How does a new transmission line affect scheduling and costs?
What are plant-specific impacts (PLFs, curtailment) based on different scenarios?

What are critical periods for followup with a power flow analysis, and what is the generation status of each plant during these periods?

What flexibility is required of the system under different future scenarios?

What technologies or systematic changes could benefit the system most?
The production cost model built for this study is ready for you to use! 


\section{Next Steps to Improve the Model for State Planning}

The production cost model used in this study has been built to assess region- and nationwide trends, and lacks some of the plant-specific detail that will be more important if the model is used for planning at the state level. Further improvements are suggested for use at the state level:

Input load specific to each substation level

\section{Current model allocates a statewide}

load to each substation proportionate to peak

Modify load shapes to reflect expected changes to appliance ownership and other usage patterns

Current model uses 2014 load shape, scaled up to 2022 peak demand

Revise RE locations and transmission plans as investments evolve

Current model uses best RE locations within the state based on suitable land availability; transmission plans are based on CEA's 202I-2022 PSS/E model and

do not reflect anticipated changes to

in-state transmission to meet new RE

Improve generator-specific parameters (e.g., variable costs, minimum up/down time, hub heights, must run status)

Current model uses generator-specific information when available, but also relies on averages (e.g., all utility PV employs fixed tracking)

Create plant-specific allocations of central generations

Current model allocates all central plant generating capacity to the host state
Allocate balancing responsibility for new RE plants to host state versus offtaker state or central entity

Current model allocates responsibility

for balancing to host state

Create an equivalent but computationally simpler representation of transmission in states or regions where operations do not affect focus area

Current model includes level of detail for the country that may be unnecessary for a specific state, creating computational challenges 


\section{Supplemental information on study assumptions}

Total generation capacity in Tamil Nadu (GW) in the I00S-60W scenario

\begin{tabular}{lcc}
\hline & OWNERSHIP & TOTAL CAPACITY (GW) \\
\hline Gas CC & State/Private & 0.7 \\
\hline Gas CT & State/Private & 0.7 \\
\hline Hydro & State/Private & 2.0 \\
\hline Nuclear & Central & 3.4 \\
\hline Other & State/Private & 0.6 \\
\hline Sub-Coal & Central & 5.7 \\
\hline Sub-Coal & State/Private & 8.5 \\
\hline Super-Coal & State/Private & 2.0 \\
\hline Total non-RE & & 23.6 \\
\hline Solar-PV & State/Private & 12.0 \\
\hline Wind & State/Private & 12.0 \\
\hline Total RE & & 24.0 \\
\hline Total capacity & & $\mathbf{4 7 . 6}$
\end{tabular}




\begin{tabular}{lcc}
\hline $\begin{array}{l}\text { Total capacity (surge impedance limit [SIL]) of transmission } \\
\text { lines connecting Tamil Nadu to other states }\end{array}$ \\
$\begin{array}{l}* \text { To evacuate new RE capacity, transmission was added in this study to } \\
\text { supplement CEA plans for 2022. }\end{array}$ & VOLTAGE (kV) & NO. LINES \\
\hline CONNECTING & 230 & 2 \\
\hline Tamil Nadu to Andhra Pradesh & 400 & 9 \\
\hline Tamil Nadu to Andhra Pradesh & 765 & 6 \\
\hline Tamil Nadu to Andhra Pradesh & 400 & 2 \\
\hline Tamil Nadu to Chhattisgarh & 230 & 1 \\
\hline Tamil Nadu to Karnataka & 400 & 10 \\
\hline Tamil Nadu to Karnataka & 230 & 5 \\
\hline Tamil Nadu to Kerala & 400 & 19 \\
\hline Tamil Nadu to Kerala* & 230 & 6 \\
\hline Tamil Nadu to Puducherry & 400 & 2 \\
\hline Tamil Nadu to Puducherry & & 62 \\
\hline Total import/export capacity & & 6 \\
\hline
\end{tabular}

Total capacity (SIL) of transmission lines within Tamil Nadu *To evacuate new RE capacity, transmission was added in this study to supplement CEA plans for 2022.

\begin{tabular}{lcc}
\hline CONNECTING & VOLTAGE $(\mathbf{k V})$ & NO. LINES \\
\hline Intrastate & 110 & 87 \\
\hline Intrastate & 230 & 423 \\
\hline Intrastate* & 400 & 194 \\
\hline Intrastate* & 765 & 25 \\
\hline Total intrastate capacity & & $\mathbf{7 2 9}$ \\
\hline
\end{tabular}




\begin{tabular}{|c|c|c|}
\hline \multicolumn{3}{|c|}{ RE capacity by substation and type } \\
\hline $\begin{array}{l}\text { SUBSTATION } \\
\text { (NUMBER_NAME_VOLTAGE) }\end{array}$ & SOLAR-PV (MW) & WIND (MW) \\
\hline 5420I4_ARASUR2_230 & 808 & 2,881 \\
\hline 5420I5_JAMBNNPRM2_230 & 303 & 94 \\
\hline 542064_THENI2_230 & 0 & 487 \\
\hline 542105_KNARPT-W_230 & 91 & 2,369 \\
\hline 542II2_VALUTHUR2_230 & 58 & 0 \\
\hline 542II4_ANIKDV-W_230 & 0 & 1,119 \\
\hline 542II8_SADAYMPLYM-W_230 & ।,131 & 238 \\
\hline 542I70_SANKARPURI_230 & 24 & 10 \\
\hline 544003_SALE_400 & 773 & 156 \\
\hline 544004_TRIC_400 & 301 & 0 \\
\hline 544005_MADURAI4_400 & 793 & 15 \\
\hline 544006_UDMP_400 & 0 & ।,344 \\
\hline 544007_HOSUR4_400 & ।,417 & 17 \\
\hline 5440I0_NEYEXTN4_400 & 0 & 120 \\
\hline 5440I2_NAGAPTNM4_400 & 86 & 0 \\
\hline
\end{tabular}

\begin{tabular}{|c|c|c|}
\hline \multicolumn{3}{|c|}{ RE capacity by substation and type } \\
\hline $\begin{array}{l}\text { SUBSTATION } \\
\text { (NUMBER_NAME_VOLTAGE) }\end{array}$ & SOLAR-PV (MW) & WIND (MW) \\
\hline 5440I3_PUGALUR4_400 & 549 & 68 \\
\hline 5440I4_ARSUR4_400 & 1,740 & 596 \\
\hline 5440I7_KARAIK_400 & 206 & 0 \\
\hline 5440I8_TIRUNEL4_400 & 0 & 232 \\
\hline 54402I_KUDAN4_400 & 416 & 877 \\
\hline 544025_TIRUNVLPOOL_400 & 0 & 642 \\
\hline 544027_KAYATHAR4_400 & 16 & 351 \\
\hline 54404I_METTUR4_400 & 536 & 5 \\
\hline 54407I_TUTICORN_400 & 600 & 37 \\
\hline 544086_MALEKTT_400 & 707 & 107 \\
\hline 544087_TIRUVLM_400 & 63 & 0 \\
\hline 544088_VALLURTPS_400 & 1,091 & 10 \\
\hline 544095_TUTI-POOL_400 & 284 & 116 \\
\hline 544133_GUINDY4_400 & 434 & 0 \\
\hline Total RE capacity & 12,427 & II,89| \\
\hline
\end{tabular}




\begin{tabular}{lcc}
\hline \multicolumn{2}{c}{ Annual energy generation fuel type, No New RE and I O0S-60W } \\
\hline & I00S-60W (TWh) & NO NEW RE (TWh) \\
\hline Gas CC & 2 & 3 \\
\hline Gas CT & 2 & 4 \\
\hline Hydro & 3 & 3 \\
\hline Nuclear & 21 & 21 \\
\hline Other & 2 & 2 \\
\hline Solar-PV: rooftop & 6 & 0 \\
\hline Solar-PV: utility scale & 15 & 0 \\
\hline Sub-Coal & 59 & 83 \\
\hline Super-Coal & 4 & 10 \\
\hline Wind & 40 & 20 \\
\hline Total Generation & 154 & 145 \\
\hline Imports & 37 & 52 \\
\hline Exports & 33 & 39 \\
\hline RE Curtailment & 3 & 0 \\
\hline
\end{tabular}

